- Original Article

\title{
The Relationship between Psychological Factors and Weight Gain
}

\author{
Hye Jin Jang, Byung Sung Kim*, Chang Won Won, Sun Young Kim, Myung Weon Seo \\ Department of Family Medicine, Kyung Hee University Medical Center, Seoul, Korea
}

See editorial commentary page on $\mathbf{3 6 3}$

Background: This study aimed to investigate stress, depression, sleeping time, physical activity, and dietary patterns as factors causing weight gain and investigate which of these factors have a greater effect on weight gain.

Methods: Data were obtained from the seventh Korea National Health and Nutrition Examination Survey, 2016. Among the respondents, 3,163 adults aged 19-64 years were included in the survey, after excluding non-responders and those with diseases that may affect weight change. The t-test and chi-square test were used to analyze the relationship between weight gain and general characteristics. Logistic regression analysis was performed to evaluate weight changes according to stress, depression, sleep time, physical activity, and dietary patterns and evaluate the odds ratios (ORs) for measuring these associations.

Results: Participants in the weight gain group were younger and more likely to be obese than those in the control group. Factors that could cause weight gain among women were stress awareness (OR, 1.271; 95\% confidence interval [CI], 1.012-1.597), physical inactivity (OR, 1.250; 95\% CI, 1.018-1.535), and skipping breakfast (OR, 1.277; 95\% CI, 1.028-1.587). Depression was significantly associated with weight gain among women, but not after adjusting for other variables. There were no significant associations with sleeping time. None of these factors in men were significantly associated with weight gain.

Conclusion: Stress awareness was significantly associated with weight gain among women, while other psychological factors were not significantly associated with weight gain.

Keywords: Weight Gain; Stress; Depression; Exercise; Diet

Received: May 17, 2019, Revised: August 19, 2019, Accepted: January 20, 2020

*Corresponding Author: Byung Sung Kim https://orcid.org/0000-0002-3293-9640

Tel: +82-2-958-8700, Fax: +82-2-958-8699, E-mail: bskim7@khmc.or.kr 


\section{INTRODUCTION}

The prevalence of obesity is increasing gradually due to various causes such as stress, sleep deprivation, physical inactivity, and high-fat diets. Obesity increases the risk of various diseases among adults, including cardiovascular diseases; ${ }^{1)}$ thus, there is growing interest in weight control and many people are becoming increasingly concerned about their weight.

Dietary control and physical activity have traditionally been the main methods of preventing and treating obesity. Recently, it has been suggested that psychological factors may also affect weight gain. Stress, due to the body's stress response system and cortisol release, has been suggested as a factor that could lead to weight gain. ${ }^{2)}$ In addition, some studies have found relationships among cortisol levels, metabolic syndrome, and insulin resistance, suggesting that stress can lead to weight gain. ${ }^{3)}$ Chronic stress has been linked to conscious food consumption in both animals and humans, particularly women. ${ }^{4)}$ Some studies have suggested that obesity may be the result of chronic maladjustment to environmental stressors in susceptible individuals. 5)

Studies have also shown that depression leads to weight gain. ${ }^{6)}$ The secretion of serotonin in the brain appears to affect mood and appetite. Depression is assumed to cause obesity indirectly through actions such as emotional eating habits and reduced physical activity. ${ }^{7,8)}$ Pharmacologic interventions that improve serotonin neurotransmission have been effective in reducing excessive intake of carbohydrates in response to the need to improve mood. ${ }^{9,10)}$

Adult women are more likely to gain weight when they spend less time sleeping. ${ }^{11)}$ A cross-sectional study of adults has shown that persons who sleep less than 7 hours per night are more likely to be obese. ${ }^{12)}$ Another study found a correlation between sleep time and future weight. ${ }^{13)}$ Many studies have assessed factors that cause weight gain; however, few have investigated which factors have the greatest effects on weight gain.

The purpose of the present study was to investigate the relative effects of psychological factors such as stress and depression, sleeping time, physical activity, and dietary pattern on weight gain among Korean adults, based on the questionnaire of the Korea National Health and Nutrition Examination Survey (KNHANES) (2016).

\section{METHODS}

\section{Study Population}

We conducted a cross-sectional study among Korean adults aged 1964 years who participated in the 2016 KNHANES. Among 4,750 adults who participated in the survey, we excluded 1,151 persons who did not respond to all items in the survey. Then, we excluded 436 subjects with cancer, diabetes, thyroid diseases, chronic kidney diseases, and cerebrovascular accident, as these may affect weight change. Finally, we included 3,163 participants who completed the health survey sections on all questionnaires in this study.

\section{Variables and Measurements}

\section{1) General characteristics}

Age, gender, household income, education level, smoking status, and alcohol consumption were surveyed through questionnaires. Body mass index (BMI) was calculated by dividing the body weight in kilogram by the square of the height in meters. Obesity was defined as a BMI cutoff point of $\geq 25.0 \mathrm{~kg} / \mathrm{m}^{2}$ using World Health Organization (WHO) Asia Pacific criteria. ${ }^{14)}$ Smoking status comprised two categories: "current smoker" or "not a current smoker." According to the frequency of alcohol consumption, subjects were classified into two groups: $\geq 1$ time/mo and $<1$ time/mo. The monthly drinking rate was a key index in the KNHANES (2016). The level of education and income were examined as indicators of socioeconomic status. Educational level comprised four categories: completed elementary school or lower, completed middle school, completed high school, and completed university or higher. The income levels of subjects were determined by classifying the income data for the study population into four quartiles: lowest, mid-low, mid-high, and highest. We also used a self-report questionnaire to survey women for menopause; women were categorized into two groups based on their responses.

\section{2) Assessment of weight gain}

Weight was not measured directly; it was based on a self-report questionnaire. The subjects were asked to compare their weight at the time of the survey with their weight recalled from 1 year ago and respond to questions about the change in body weight over the past year. A change of less than $3 \mathrm{~kg}$ was considered to indicate no change in body weight. The weight gain group was defined as subjects who gained weight of $3 \mathrm{~kg}$ or more. Those who did not gain weight or gained weight less than $3 \mathrm{~kg}$ were classified as the control group.

\section{3) Psychological factors}

Regarding stress awareness, the participants were classified into a stress-aware group and a non-stress-aware group. The participants were asked "How often do you feel stress in your daily life?" and selected one of the four choices on the questionnaire. The stress-aware group included participants who responded that they felt "very much" or "much" stress in their everyday lives.

Clinical depression was assessed using the 9-item Patient Health Questionnaire (PHQ-9) for screening depression. ${ }^{15)}$ The PHQ-9 is a reliable test with high sensitivity and specificity and can be used to screen major depressive disorders. ${ }^{16)}$ The cutoff point of the PHQ-9 for depression is 10 points, and a score of 10 points or more is used as a criterion for determining major depressive disorder. In the present study, the same criteria were applied.

Sleep time was measured as the length of time (in minutes) between when the participants fell asleep and when they woke up. The participants were required to respond to the question "What is your usual bedtime (during week days) and when do you go to bed? 


\section{4) Physical activity and dietary patterns}

Physical activity was assessed as the rate of aerobic physical activity. The WHO recommends that adults older than 18 years should engage in at least 150 minutes of moderate-intensity physical activity throughout the week, at least 75 minutes of vigorous-intensity physical activity throughout the week, or an equivalent combination of moderate- and vigorous-intensity activity. ${ }^{17)}$ In the present study, the same criteria were applied, such that participants were divided into two groups based on those who met the recommendations of the WHO for physical activity, and those who did not.

Dietary patterns were determined by the number of meals and frequency of eating out. The question of whether or not breakfast was eaten was included in the questionnaire about the frequency of breakfast for 1 week during the past 1 year. The subjects who ate breakfast four or fewer times per week were categorized as the breakfast skipping group and the subjects who ate breakfast 5 or more times per week were classified as the breakfast eating group. Skipping of lunch and dinner were also assessed in the survey, but those questionnaires were not included in the present study. Regarding the frequency of eating out, we summarized the subjects' responses to questions about the average frequency of eating out over the past year. Subjects who responded " 1 to 3 times a month" were categorized as subjects who ate out less than once a week. Subjects who ate out at least once a week were classified as eating out $\geq 1$ time/wk.

\section{Statistical Analysis}

For the analysis of baseline characteristics, the data were summarized as numbers and percentages. The chi-square test was used to compare general characteristics of the subjects. Logistic regression analysis was used to determine the relationship between weight gain and psychological factors, exercise, and dietary patterns and evaluate the odds ratios (ORs) for measuring these associations. Model 1 was adjusted for age and sex. Model 2 was adjusted for age, sex, BMI, household income, educational level, and lifestyle habits (including smoking and alcohol consumption). All data analyses were performed using IBM SPSS ver. 25.0 for Windows (IBM Corp., Armonk, NY, USA). A P-value $<0.05$ was considered statistically significant.

This study plan was approved by the Institutional Review Board of the Kyung Hee University, and written consent was obtained from subject prior to commencement of the study (IRB approval no., 201903-048).

\section{RESULTS}

\section{Baseline Characteristics}

Of the 3,163 subjects, 1,278 were men and 1,885 were women. Among the male subjects, 329 (25.7\%) were part of the weight gain group (Table 1). Among men, participants in the weight gain group were younger and more likely to be obese than those in the control group, and the proportion of participants with an education level below junior high school was lower than that in the control group $(\mathrm{P}<0.001)$. The weight gain group also included a greater number of subjects who were stressaware $(\mathrm{P}=0.004)$ and skipped breakfast $(\mathrm{P}<0.001)$ than the control group. However, there were no significant differences in the distributions of depression $(\mathrm{P}=0.281)$, sleeping time $(\mathrm{P}=0.641)$, physical activity $(\mathrm{P}=1.000)$, or frequency of eating out $(\mathrm{P}=0.084)$ between the groups.

Among female subjects, 633 (33.5\%) were part of the weight gain group (Table 2). Similar to the results obtained for the male group, the female weight gain group had younger participants, a higher rate of obesity, and a higher percentage of educated people $(\mathrm{P}<0.05)$ than did the control group. In addition, the proportion of menopausal women in the weight gain group was significantly lower $(\mathrm{P}<0.001)$ than that in the control group. Women in the weight gain group were also more

Table 1. Distribution of baseline characteristics (among men)

\begin{tabular}{|c|c|c|c|}
\hline Characteristic & $\begin{array}{l}\text { Weight gain* } \\
\quad(n=329)\end{array}$ & $\begin{array}{l}\text { No weight gain } \\
\quad(n=949)\end{array}$ & $P$-value ${ }^{\dagger}$ \\
\hline Age (y) & $36.4 \pm 11.3$ & $44.3 \pm 11.9$ & $<0.001$ \\
\hline Body mass index $\left(\mathrm{kg} / \mathrm{m}^{2}\right)$ & & & $<0.001$ \\
\hline$<25.0$ & $126(38.3)$ & $596(62.8)$ & \\
\hline$\geq 25.0$ & $203(61.7)$ & $353(37.2)$ & \\
\hline Smoking status & & & 0.896 \\
\hline Non-current smoker & $196(59.6)$ & $571(60.2)$ & \\
\hline Current smoker & $133(40.4)$ & $378(39.8)$ & \\
\hline Alcohol intake (time/mo) & & & 0.603 \\
\hline$<1$ & $77(23.4)$ & $238(25.1)$ & \\
\hline$\geq 1$ & $252(76.6)$ & $711(74.9)$ & \\
\hline Household income & & & 0.284 \\
\hline Low & $32(9.7)$ & $73(15.6)$ & \\
\hline Mid-low & $83(25.2)$ & $216(22.8)$ & \\
\hline Mid-high & 106 (32.2) & $298(31.4)$ & \\
\hline High & $108(32.8)$ & $362(38.1)$ & \\
\hline Education level & & & $<0.001$ \\
\hline Elementary school or lower & $8(2.4)$ & $59(6.2)$ & \\
\hline Middle school & $15(4.9)$ & $68(7.2)$ & \\
\hline High school & $148(45.0)$ & $312(32.9)$ & \\
\hline University or higher & $157(47.7)$ & $510(53.7)$ & \\
\hline Stress awareness & & & 0.004 \\
\hline Stress aware & $215(65.3)$ & $700(73.8)$ & \\
\hline Non-stress aware & $114(34.7)$ & $249(26.2)$ & \\
\hline 9-Item Patient Health Questionnaire & & & 0.281 \\
\hline Normal $(<10)$ & $315(95.7)$ & $921(97.0)$ & \\
\hline Depressed $(\geq 10)$ & $14(4.3)$ & $28(3.0)$ & \\
\hline Sleeping time & $428.6 \pm 67.2$ & $426.6 \pm 67.9$ & 0.641 \\
\hline Physical activity & & & 1.000 \\
\hline No & $159(48.3)$ & $459(48.4)$ & \\
\hline Yes & $170(51.7)$ & $490(51.6)$ & \\
\hline \multicolumn{4}{|l|}{ Dietary pattern } \\
\hline Skipping breakfast (times/wk) & & & $<0.001$ \\
\hline$<3$ & $135(41.0)$ & $561(59.1)$ & \\
\hline$\geq 3$ & $194(59.0)$ & $388(40.9)$ & \\
\hline Eating out (times/wk) & & & 0.084 \\
\hline$<1$ & $20(6.1)$ & $88(9.3)$ & \\
\hline$\geq 1$ & $309(93.9)$ & $861(90.7)$ & \\
\hline
\end{tabular}

Values are presented as mean \pm standard deviation for continuous variables or number (\%) for categorical variables.

*The weight gain group was defined as a weight gain of $3 \mathrm{~kg}$ or more over a 1-year period. ${ }^{\dagger}$ Calculated using a Pearson's chi-square test. 
Table 2. Distribution of baseline characteristics (among women)

\begin{tabular}{|c|c|c|c|}
\hline Characteristic & $\begin{array}{l}\text { Weight gain* }^{*} \\
\qquad(\mathrm{n}=633)\end{array}$ & $\begin{array}{l}\text { No weight gain } \\
\quad(n=1,252)\end{array}$ & P-value ${ }^{\dagger}$ \\
\hline Age (y) & $40.5 \pm 11.5$ & $43.8 \pm 12.5$ & $<0.001$ \\
\hline Body mass index $\left(\mathrm{kg} / \mathrm{m}^{2}\right)$ & & & $<0.001$ \\
\hline$<25.0$ & $377(59.6)$ & $1,019(81.4)$ & \\
\hline$\geq 25.0$ & $256(40.4)$ & $233(18.6)$ & \\
\hline Menopause & & & $<0.001$ \\
\hline No & $489(77.3)$ & $815(65.1)$ & \\
\hline Yes & $144(22.7)$ & $437(34.9)$ & \\
\hline Smoking status & & & 0.023 \\
\hline Non-current smoker & 584 (92.3) & $1,189(95.0)$ & \\
\hline Current smoker & $49(7.7)$ & $63(5.0)$ & \\
\hline Alcohol intake (time/mo) & & & 0.032 \\
\hline$<1$ & $291(46.0)$ & $642(51.3)$ & \\
\hline$\geq 1$ & $342(54.0)$ & $610(48.7)$ & \\
\hline Household income & & & 0.407 \\
\hline Low & $59(9.3)$ & $104(8.3)$ & \\
\hline Mid-low & $161(25.4)$ & $296(23.6)$ & \\
\hline Mid-high & $204(32.2)$ & $391(31.2)$ & \\
\hline High & $209(33.0)$ & $461(36.8)$ & \\
\hline Education level & & & 0.012 \\
\hline Elementary school or lower & $50(7.9)$ & $121(9.7)$ & \\
\hline Middle school & $54(8.5)$ & $112(8.9)$ & \\
\hline High school & $214(33.8)$ & 494 (39.5) & \\
\hline University or higher & $315(49.8)$ & $525(41.9)$ & \\
\hline Stress awareness & & & $<0.001$ \\
\hline Stress aware & $404(63.8)$ & $904(72.2)$ & \\
\hline Non-stress aware & $229(36.2)$ & $348(27.8)$ & \\
\hline 9-Item Patient Health Questionnaire & & & 0.024 \\
\hline Normal $(<10)$ & $587(92.7)$ & $1,194(95.4)$ & \\
\hline Depressed $(\geq 10)$ & $46(7.3)$ & $58(4.6)$ & \\
\hline Sleeping time & $434.7 \pm 74.3$ & $434.5 \pm 72.3$ & 0.952 \\
\hline Physical activity & & & 0.045 \\
\hline No & $359(56.7)$ & $649(51.8)$ & \\
\hline Yes & $274(43.3)$ & $603(48.2)$ & \\
\hline \multicolumn{4}{|l|}{ Dietary pattern } \\
\hline Skipping breakfast (times/wk) & & & $<0.001$ \\
\hline$<3$ & 305 (48.2) & $754(60.2)$ & \\
\hline$\geq 3$ & $328(51.8)$ & $498(39.8)$ & \\
\hline Eating out (time/wk) & & & 0.007 \\
\hline$<1$ & $126(19.9)$ & $319(25.5)$ & \\
\hline$\geq 1$ & $507(80.1)$ & $933(74.5)$ & \\
\hline
\end{tabular}

Values are presented as mean \pm standard deviation for continuous variables or number (\%) for categorical variables.

${ }^{*}$ The weight gain group was defined as a weight gain of $3 \mathrm{~kg}$ or more over a 1-year period. ${ }^{\dagger}$ Calculated using a Pearson's chi-square test.

likely to drink and smoke than women in the control group. As with men, women in the weight gain group had greater stress awareness and were more likely to skip breakfast than women in the control group $(\mathrm{P}<0.001)$. Among women, the greater the degree of depression and the frequency of eating out, the greater was the weight gain $(\mathrm{P}<0.05)$. Among women with lower rates of physical activity, the degree of weight gain was greater $(\mathrm{P}=0.045)$.

\section{Association between Weight Gain and Psychological Factors}

Table 3 shows the results of a logistic regression analysis of the association between weight gain and psychological factors, physical activity, and dietary pattern among men. In model 1 , five factors were compared after adjusting for age. None of these factors had a significant impact on weight gain among men. Of these factors, skipping breakfast had the greatest impact, with an odds ratio of 1.271 for weight gain; however, this increased risk was not statistically significant (OR, 1.271; 95\% confidence interval [CI], 0.960-1.684). Model 2 considered five factors associated with weight gain while adjusting for BMI, household income, education level, alcohol intake, and smoking status; however, the model revealed no significant relationships between weight gain and any of the factors. However, age and obesity significantly affected weight gain among men.

Table 4 shows the results of a logistic regression analysis of the relationships among weight gain and psychological factors, physical activity, and dietary pattern in women. In model 1 , stress awareness (OR, 1.285; 95\% CI, 1.033-1.599), physical inactivity (OR, 1.248; 95\% CI, 1.025-1.520), and skipping breakfast (OR, 1.335; 95\% CI, 1.084-1.645) were significantly associated with weight gain, even after adjusting for age. Of these factors, skipping breakfast had the greatest impact, increasing the risk of weight gain by 1.335 times. The risk ratio was 1.285 for stress awareness and 1.248 for physical inactivity. Model 2 was adjusted for the remaining baseline characteristics summarized in Table 3. All three factors that were significant in model 1 (stress awareness, physical inactivity, and skipping breakfast) remained significant in model 2. Among these factors, skipping breakfast had the greatest impact on weight gain, increasing the risk by 1.277 . The risk ratio was 1.271 for stress awareness and 1.250 for physical activity.

\section{DISCUSSION}

The present study compared the association between weight gain and psychological factors among Korean adults aged 19-64 years who participated in the 2016 KNHANES. Three factors were found to be significantly associated with weight gain among women: stress awareness, physical inactivity, and skipping breakfast. Women tended to gain weight when they felt stressed. Reduced frequency of physical activity and increased frequency of skipping breakfast were also associated with weight gain. Depression was significantly associated with weight gain, but not after adjusting for other variables. Weight gain was not associated with sleeping time. None of these factors were significantly associated with weight gain in men.

According to previous studies, stress increases food intake among women and women are more likely to experience relapse in weight gain and overeating after achieving weight loss by dieting., ${ }^{4,18)}$ The results of the present study are consistent with previously published findings. A woman's stress awareness and her weight gain were positively correlated. Stress was more strongly related to weight gain than lower physical activity, indicating that psychological factors may con- 
Table 3. Logistic regression analysis of psychological factors for weight gain (among men)

\begin{tabular}{|c|c|c|c|c|}
\hline \multirow{2}{*}{ Variable } & \multicolumn{2}{|c|}{ Model 1} & \multicolumn{2}{|c|}{ Model 2} \\
\hline & OR $(95 \% \mathrm{Cl})$ & P-value & OR $(95 \% \mathrm{Cl})$ & $\mathrm{P}$-value \\
\hline Stress awareness & $1.29(0.96-1.72)$ & 0.081 & $1.21(0.89-1.63)$ & 0.212 \\
\hline Depression (PHQ-9 $\geq 10)$ & $1.10(0.54-2.21)$ & 0.791 & $1.14(0.54-2.38)$ & 0.720 \\
\hline Sleeping time & $0.99(0.99-1.00)$ & 0.573 & $1.00(0.99-1.00)$ & 0.692 \\
\hline Physical activity (no vs. yes) & $1.23(0.94-1.61)$ & 0.122 & $1.24(0.94-1.64)$ & 0.123 \\
\hline Skipping breakfast & $1.27(0.96-1.68)$ & 0.094 & $1.27(0.94-1.70)$ & 0.110 \\
\hline Eating out & $1.09(0.64-1.87)$ & 0.739 & $1.17(0.67-2.03)$ & 0.580 \\
\hline Age & $0.94(0.93-0.96)$ & 0.000 & $0.94(0.93-0.95)$ & 0.000 \\
\hline BMI $\left(\geq 25.0 \mathrm{~kg} / \mathrm{m}^{2}\right)$ & & & $2.95(2.24-3.88)$ & 0.000 \\
\hline Household income (higher vs. lower) & & & $0.84(0.62-1.13)$ & 0.265 \\
\hline Education level (২high school) & & & $0.88(0.52-1.49)$ & 0.643 \\
\hline Alcohol intake & & & $1.08(0.77-1.50)$ & 0.644 \\
\hline Smoking status & & & $0.89(0.66-1.19)$ & 0.439 \\
\hline
\end{tabular}

Model 1: adjusted for age; model 2: adjusted for age, BMl, household income, education level, alcohol intake, and smoking status.

$\mathrm{OR}$, odds ratio; $\mathrm{Cl}$, confidence interval; $\mathrm{PHQ}-9$, 9-item patient health questionnaire; $\mathrm{BMI}$, body mass index.

Table 4. Logistic regression analysis of psychological factors for weight gain (among women)

\begin{tabular}{|c|c|c|c|c|}
\hline \multirow{2}{*}{ Variable } & \multicolumn{2}{|c|}{ Model 1} & \multicolumn{2}{|c|}{ Model 2} \\
\hline & OR (95\% Cl) & P-value & OR (95\% Cl) & P-value \\
\hline Stress awareness & $1.285(1.033-1.599)$ & 0.024 & $1.271(1.012-1.597)$ & 0.039 \\
\hline Depression (PHQ-9 $\geq 10)$ & $1.272(0.830-1.948)$ & 0.270 & $1.240(0.790-1.948)$ & 0.349 \\
\hline Sleeping time & $0.999(0.998-1.001)$ & 0.463 & $1.000(0.998-1.001)$ & 0.768 \\
\hline Physical activity (no vs. yes) & $1.248(1.025-1.520)$ & 0.027 & $1.250(1.018-1.535)$ & 0.033 \\
\hline Skipping breakfast & $1.335(1.084-1.645)$ & 0.007 & $1.277(1.028-1.587)$ & 0.027 \\
\hline Eating out & $1.174(0.918-1.501)$ & 0.201 & $1.248(0.958-1.626)$ & 0.101 \\
\hline Age & $0.984(0.975-0.993)$ & 0.000 & $0.985(0.972-0.999)$ & 0.032 \\
\hline Menopause & & & $0.642(0.444-0.928)$ & 0.018 \\
\hline $\mathrm{BMl}\left(\geq 25.0 \mathrm{~kg} / \mathrm{m}^{2}\right)$ & & & $3.448(2.746-4.329)$ & 0.000 \\
\hline Household income (higher vs. lower) & & & $0.921(0.738-1.151)$ & 0.471 \\
\hline Education level ( $\geq$ high school) & & & $0.833(0.597-1.163)$ & 0.283 \\
\hline Alcohol intake & & & $1.065(0.864-1.311)$ & 0.555 \\
\hline Smoking status & & & $1.234(0.810-1.879)$ & 0.328 \\
\hline
\end{tabular}

Model 1: adjusted for age; model 2: adjusted for age, BMl, household income, education level, alcohol intake, and smoking status.

$\mathrm{OR}$, odds ratio; $\mathrm{Cl}$, confidence interval; BMI, body mass index; $\mathrm{PHQ}-9$, 9-item patient health questionnaire.

tribute to weight gain.

Other studies have reported that depression increases the risk of obesity by increasing high-density food intake. ${ }^{19)}$ In the present study, very few subjects were classified as depressed to accurately assess this relationship.

Previous studies have shown that sleep deprivation can alter serum leptin and ghrelin levels, resulting in increased hunger and appetite. ${ }^{20)}$ We predicted that men and women would show greater weight gain as sleep time decreased; however, these relationships were not significant in the present study.

There was also a significant correlation between decreasing frequency of physical activity and increasing body weight in women. This finding was consistent with the traditional effect of exercise on body weight. A previous longitudinal study examined the relationship between physical activity and BMI over a 20 -year period and found that the higher the activity level among younger women, the less was the weight they gained after middle age. ${ }^{21)}$ In the present study, the degree of physical activity among women was significantly correlated with body weight.

Among women, there was a positive correlation between an increased frequency of skipping breakfast and the risk of weight gain. There are several possible explanations for this result. First, skipping breakfast may increase the likelihood of snack intake or the tendency to overeat at lunch and dinner. Due to the cross-sectional nature of the present study, it was not possible to identify precise causal relationships. Perhaps people who gained weight skipped breakfast more often to reduce weight.

Among men, there was no significant relationship between weight gain and psychological factors. In previous studies, diet and lifestyle factors were found to have a significant effect on long-term weight gain among both men and women. ${ }^{22)}$ However, there is still a lack of research on whether psychological factors are associated with weight gain in men. Therefore, further research is needed on this later.

This study had several limitations. As noted above, due to the cross- 
sectional nature of the present study, it was not possible to determine a causal relationship between weight gain and psychological factors. Second, this study used retrospective self-report questionnaires; thus, recall bias may have occurred. However, selection bias may have been lower than that among studies of hospital participants because our study focused on the general population.

In conclusion, stress awareness was significantly associated with weight gain among women, while other psychological factors were not significantly associated with weight gain. Two factors that have traditionally been associated with weight gain, including skipping breakfast and physical inactivity, were significantly correlated with weight gain in our study. Among these factors, skipping breakfast was associated with the highest risk of weight gain, followed by stress awareness.

\section{CONFLICT OF INTEREST}

No potential conflict of interest relevant to this article was reported.

\section{ORCID}

Hye Jin Jang: https://orcid.org/0000-0001-9465-5160

Byung Sung Kim: https://orcid.org/0000-0002-3293-9640

Chang Won Won: https://orcid.org/0000-0002-6429-4461

Sun Young Kim: https://orcid.org/0000-0003-4115-4455

Myung Weon Seo: https://orcid.org/0000-0002-3324-6440

\section{REFERENCES}

1. Lavie CJ, Milani RV, Ventura HO. Obesity and cardiovascular disease: risk factor, paradox, and impact of weight loss. J Am Coll Cardiol 2009;53:1925-32.

2. Wardle J, Gibson EL. Impact of stress on diet: processes and implications. In: Stansfeld S, Marmot M, editors. Stress and the heart: psychosocial pathways to coronary heart disease. London: BMJ Books; 2002. p. 124-49.

3. Dinneen S, Alzaid A, Miles J, Rizza R. Metabolic effects of the nocturnal rise in cortisol on carbohydrate metabolism in normal humans. J Clin Invest 1993;92:2283-90.

4. Adam TC, Epel ES. Stress, eating and the reward system. Physiol Behav 2007;91:449-58.

5. Bjorntorp P. Visceral obesity: a "civilization syndrome". Obes Res 1993;1:206-22.

6. Murphy JM, Horton NJ, Burke JD Jr, Monson RR, Laird NM, Lesage A, et al. Obesity and weight gain in relation to depression: findings from the Stirling County Study. Int J Obes (Lond) 2009;33:335-41.

7. Dallman MF, Pecoraro NC, la Fleur SE. Chronic stress and comfort foods: self-medication and abdominal obesity. Brain Behav Immun 2005;19:275-80.

8. Wise LA, Adams-Campbell LL, Palmer JR, Rosenberg L. Leisure time physical activity in relation to depressive symptoms in the Black Women's Health Study. Ann Behav Med 2006;32:68-76.

9. Ciarella G, Ciarella M, Graziani P, Mirante M. Changes in food consumption of obese patients induced by dietary treatment combined with dexfenfluramine. Int J Obes 1991;15:69.

10. Cangiano C, Ceci F, Cascino A, Del Ben M, Laviano A, Muscaritoli M, et al. Eating behavior and adherence to dietary prescriptions in obese adult subjects treated with 5-hydroxytryptophan. Am J Clin Nutr 1992;56:863-7.

11. Lyytikainen P, Lallukka T, Lahelma E, Rahkonen O. Sleep problems and major weight gain: a follow-up study. Int J Obes (Lond) 2011;35:109-14.

12. Gangwisch JE, Malaspina D, Boden-Albala B, Heymsfield SB. Inadequate sleep as a risk factor for obesity: analyses of the NHANES I. Sleep 2005;28:1289-96.

13. Hasler G, Buysse DJ, Klaghofer R, Gamma A, Ajdacic V, Eich D, et al. The association between short sleep duration and obesity in young adults: a 13-year prospective study. Sleep 2004;27:661-6.

14. World Health Organization. The Asia-Pacific perspective: redefining obesity and its treatment. Sydney: Health Communications Australia; 2000.

15. Kroenke K, Spitzer RL, Williams JB. The PHQ-9: validity of a brief depression severity measure. J Gen Intern Med 2001;16:606-13.

16. Park SJ, Choi HR, Choi JH, Kim KW, Hong JP. Reliability and validity of the Korean version of the Patient Health Questionnaire-9 (PHQ-9). Anxiety Mood 2010;6:119-24.

17. World Health Organization. Global recommendations on physical activity for health [Internet]. Geneva: World Health Organization; 2010 [cited 2019 Apr 3]. Available from: https://www.who.int/dietphysicalactivity/factsheet_recommendations/en/.

18. Kayman S, Bruvold W, Stern JS. Maintenance and relapse after weight loss in women: behavioral aspects. Am J Clin Nutr 1990;52:800-7.

19. Oliver G, Wardle J. Perceived effects of stress on food choice. Physiol Behav 1999;66:511-5.

20. Spiegel K, Tasali E, Penev P, Van Cauter E. Brief communication: sleep curtailment in healthy young men is associated with decreased leptin levels, elevated ghrelin levels, and increased hunger and appetite. Ann Intern Med 2004;141:846-50.

21. Hankinson AL, Daviglus ML, Bouchard C, Carnethon M, Lewis CE, Schreiner PJ, et al. Maintaining a high physical activity level over 20 years and weight gain. JAMA 2010;304:2603-10.

22. Mozaffarian D, Hao T, Rimm EB, Willett WC, Hu FB. Changes in diet and lifestyle and long-term weight gain in women and men. N Engl J Med 2011;364:2392-404. 